
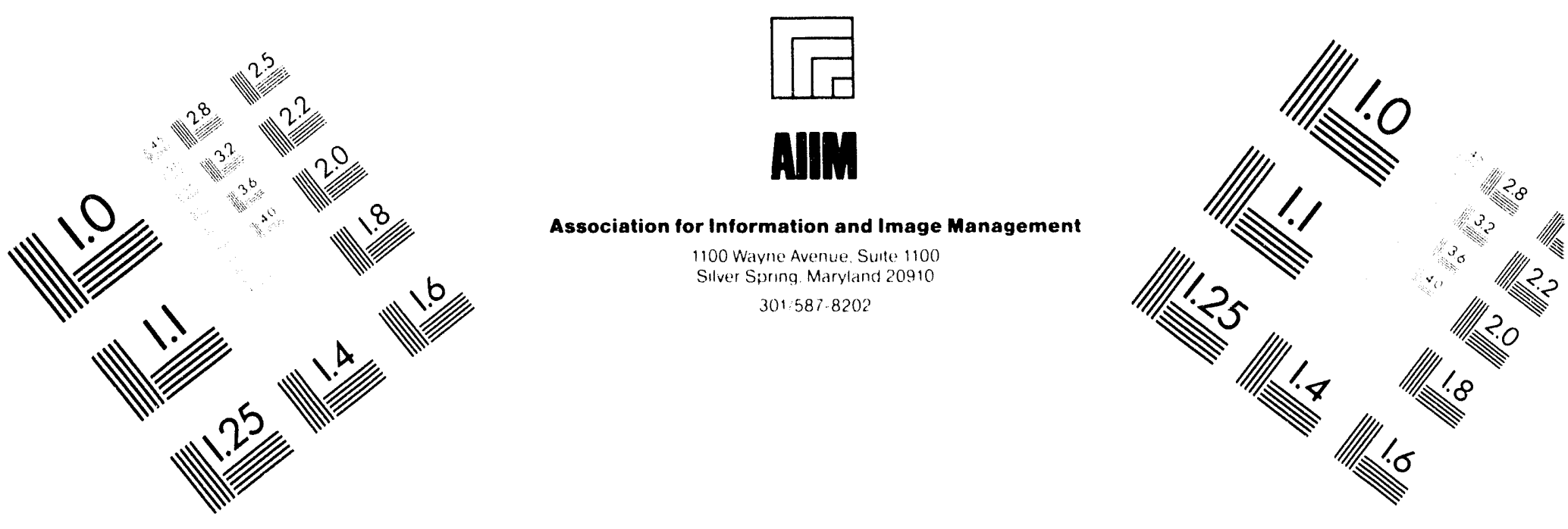

\title{
Centimeter
}

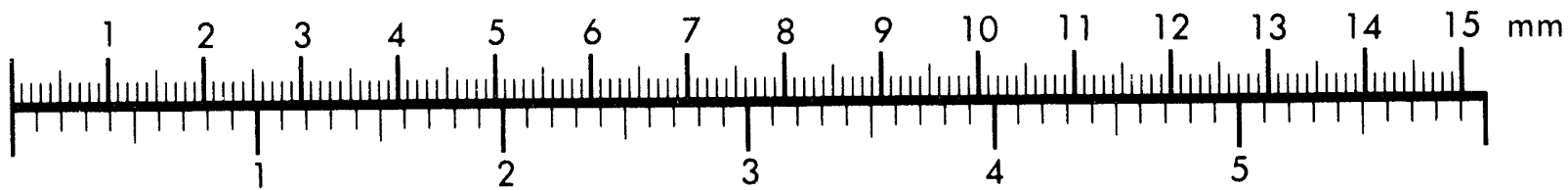

Inches
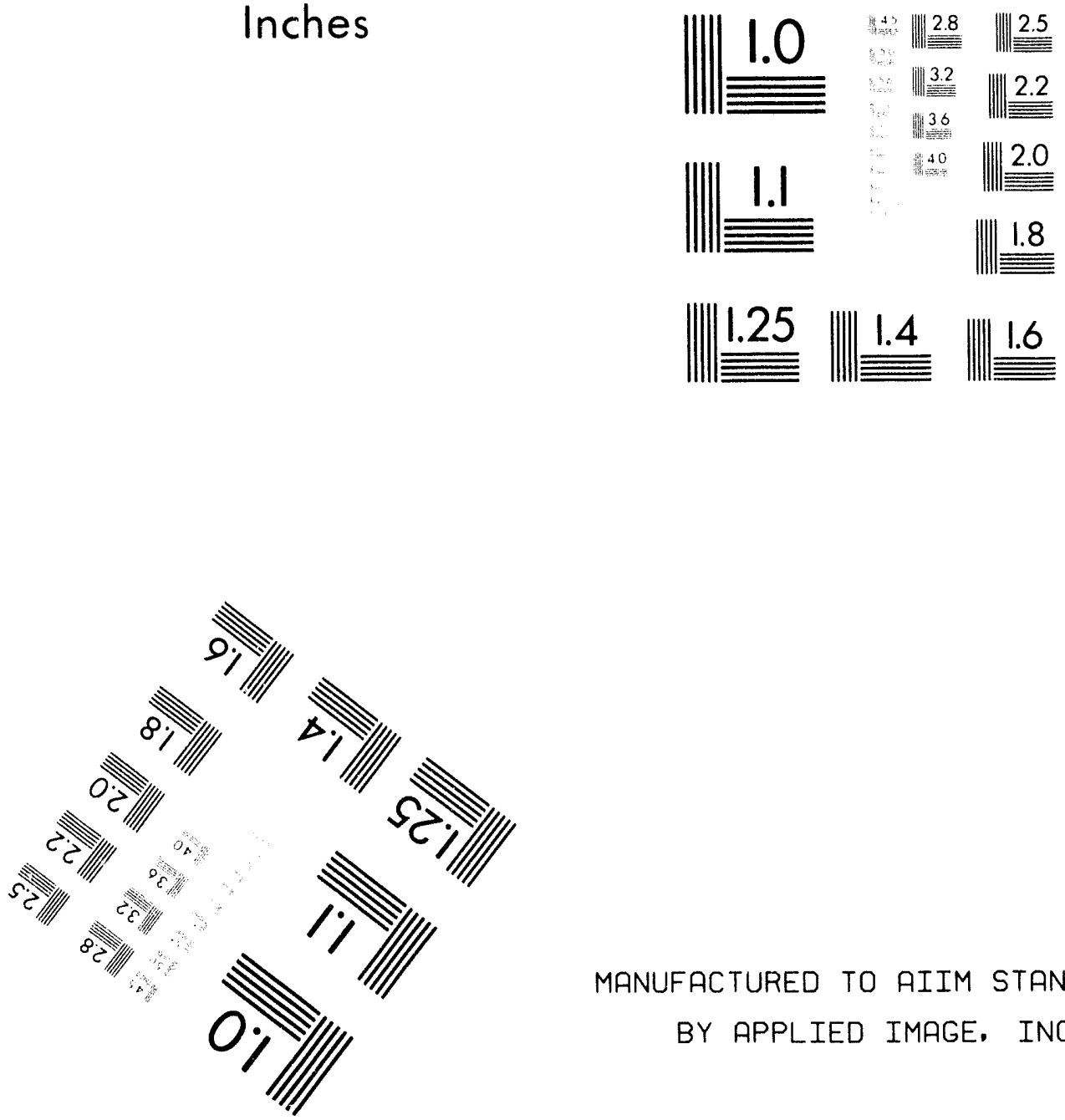

MANUFACTURED TO AIIM STANDARDS

BY APPLIED IMAGE. INC.

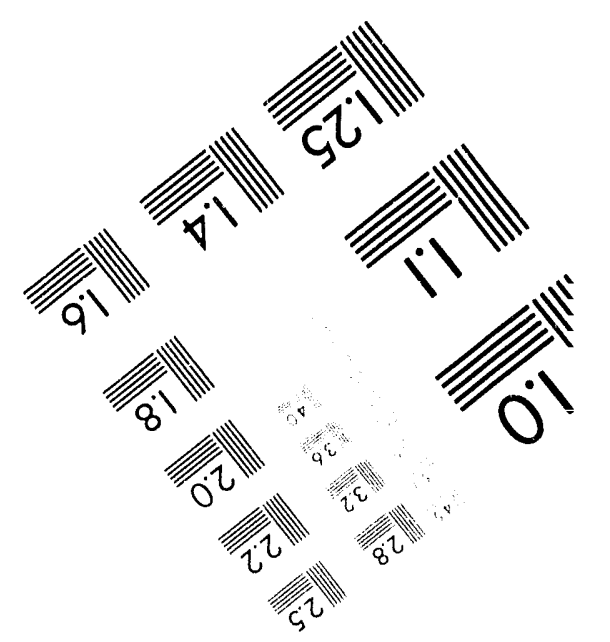



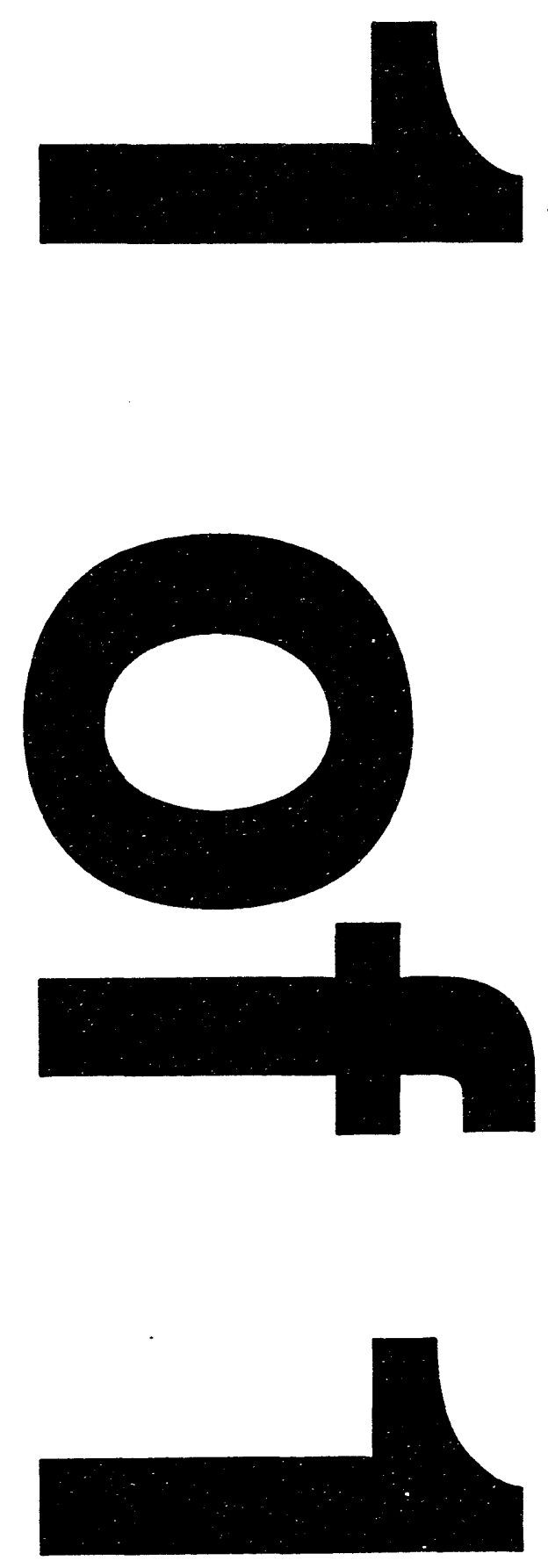
Multiquadric Collocation Methods in the Numerical Solution of Volterra Integral Equations with Weakly Singular Kernels

\author{
Athena Makroglou \\ Edward J. Kansa
}

December 1993

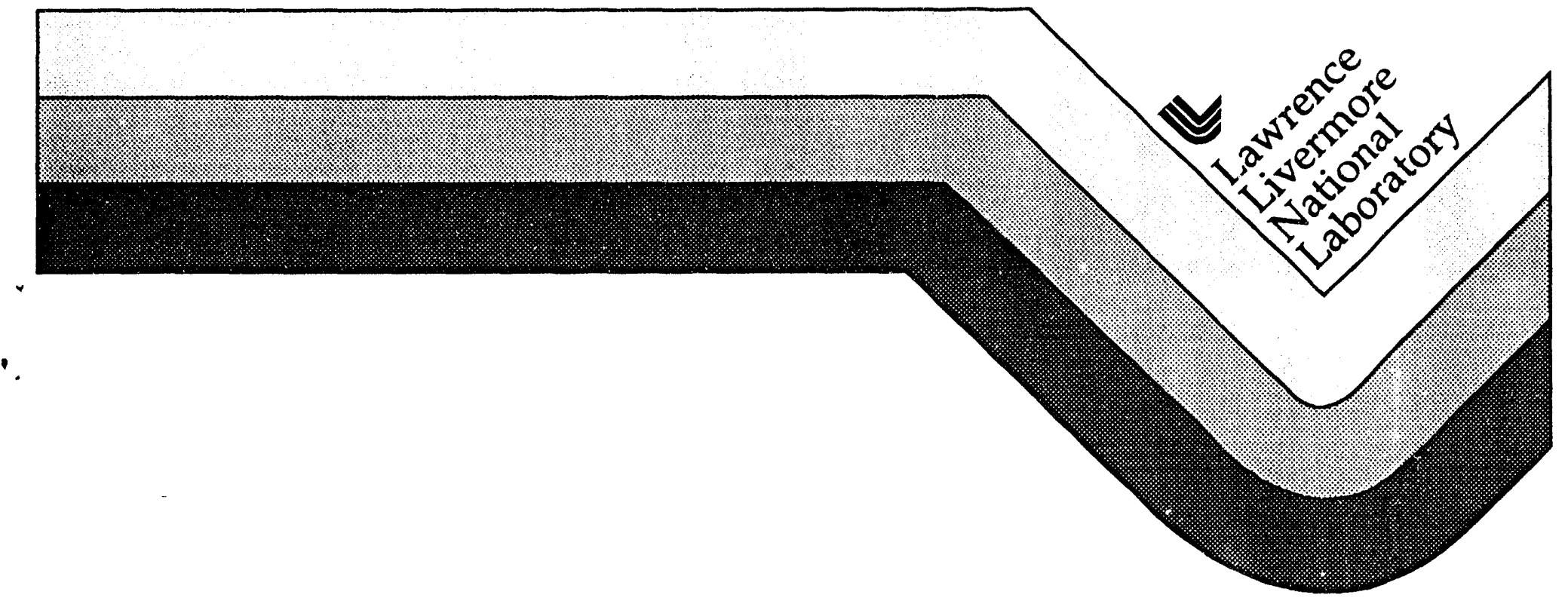

\title{
MASTER
}

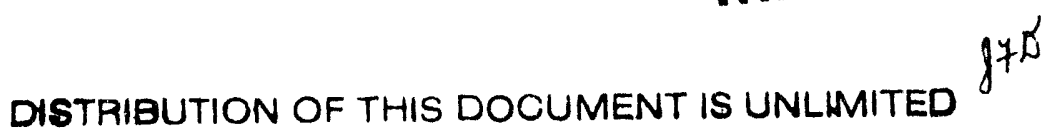


DISCLAINER

Worh performed under the auspices of the U.S. Department of Energy by lawrence Livermore National Laboratory under contract number $W-7405-E \times G-\$ 8$.

This document was prepared as an account of work sponsored by an agency of the linited States Government. Neither the Lnited States Government nor the University of California nor any of their employees. mahes any warranty, expresi or implied, or assumes any legal liability or responsibilit! for the accuracy, completeness. or usefulness of any information. apparatus, product, or process disclosed. or represents that its use would not infringe privately owned rights. Reference herein to any specific commercial products. process, or service by trade name. trademark, manufacturer. or otherwise, does not necessarily constitute or imply its endorsement, recommendation, or favoring by the United States Government or the Universits of California. The viens and opinions of authors expressed herein do not necessaril! state or reflect those of the Inited States Government or the Iniversity of California, and shall not be used for adiertising or product endorsement purpeses. 


\title{
MULTIQUADRIC COLLOCATION METHODS IN THE NUMERICAL SOLUTION OF VOLTERRA INTEGRAL EQUATIONS WITH WEAKLY SINGULAR KERNELS
}

\author{
Athena Makroglou \\ Department of Mathematics, University of Manchester, \\ Manchester M13 9PL, England, UK. \\ EDWARD J. Kansa \\ Lawrence Livermore National Laboratory, L-200, P.O. Box \\ 808, Livermore, CA 94551-9900, U.S.A.
}

\begin{abstract}
ABstruOT. Nonlinear Volterrs integral equations with weakly singular kernela are considered and are solved by applying piecewise collocation methoda based on multiquadric approximation combined with Gauns quadrature rules.
\end{abstract}

\section{INTRODU ITION}

This paper considers Volterra integral equations (VIEs) with weakly-singular kernels of the form

$$
y(x)=f(x)+\int_{0}^{x} \frac{H(x, s, y(s))}{(x-s)^{\alpha}} d s, \quad 0<\alpha<1, \quad 0 \leq x \leq X,
$$

where $y(x)$ is the unknown function to be determined, and $f(x), H(x, s, y)$ are given smooth functions. The function $\mathrm{B}$ is assumed nonlinear in $\mathrm{y}$.

We apply piecewise collocation methods based on multiquadrics (MQ) augmented with a constant term, combined with Gauss quadrature rules for the evaluation of the weakly-singular integrals.

Existing methods for the numerical solution of weakly-singular equations of the second kind include block-by-block methods (Linz [12], De Hoog and Weiss [9]), coilocation methods in certain polynomial spline spaces with equidistant and graded meshes (cf. Brunner [3]), collocation methods in non-polynomial spaces (te Riele

1980 Mathematics Subject Classification (1985 Revision). Frimary 65R20 ; Secondary 65D05.

Key words and phreses. Numerical solution, Volterrs integral, weakly-singular, multiquadrics. This paper is a summary of remuits presented at the Conference "International Conference on Scientific Computing and Modeling", Eastern Dlinoir Univentity, Charleaton IL, 3-4 Dec. 1993. The full paper will appear eleewhere when completed.

The firat author gratefully acknowledges that her part of the work of this paper was completed during a temporary visiting appointment at the Department of Mathematica, University of Manchester. 
[16], Brunner and te Riele [5]), fractional linear multistep methods (Lubich [13]), rational basis functions methods (Abelmar and Eyre [1]), sinc approximation methods (Riley [17]).

The plan of this paper is as follows. Section 2 gives a description of the application of the MQ approximations to equation (1.1). In $\$ 3$ are given numerical results, and in $\$ 4$ conclusions and comments on remaining problems.

\section{DESCRJPTION OF THE METHODS}

Consider the integral equation (1.1). In a piecewise collocation method we consider mesh points $0=x_{0}<x_{1}<\cdots<x_{N}=X$ and seek approximate values of the solution of (1.1) for $0 \leq x_{n j} \leq X$, where $x_{n j}=x_{n}+c_{j} h_{n}, h_{n}=x_{n+1}-x_{n}$ $(n=0,1, \ldots, N-1)$, and the collocation parameters are such that $0 \leq c_{1}<\cdots<$ $c_{m} \leq 1$ (for more details, see for example Brunner and van der Houwen [4]).

The form of a multiquadric augmented by a constant term which interpolates a set of points $\left(x_{i}, y_{i}\right), i=1,2, \ldots, m$, is

$$
S(x)=\sum_{j=1}^{m} a_{j} \tilde{u}_{j}(x),
$$

where

$$
\begin{gathered}
\bar{u}_{j}(x)= \begin{cases}1 & \text { if } j=1, \\
u_{j}(x)-u_{1}(x) & \text { if } j>1,\end{cases} \\
u_{j}(x)=\sqrt{\left(x-x_{j}\right)^{2}+R^{2}}
\end{gathered}
$$

and the coefficients $a_{j}$ are obtained from the solution of the linear system of equations

$$
S\left(x_{i}\right)=y_{i}, \quad i=1,2, \ldots, m .
$$

In particular we shall utilize the Lagrange-type expression of a multiquadric approximation (2.2)-(2.4). The Lagrange type expression of a multiquadric approximation for a function $\phi(x)$ is of the form

$$
S(x)=\sum_{\mu=1}^{m} I_{\mu}(x) \phi\left(x_{\mu}\right)
$$

where

$$
l_{\mu}(x)=\sum_{\lambda=1}^{m} Q_{\mu \lambda} \bar{u}_{\lambda}(x),
$$

and the constants $Q_{\mu \lambda}$ can be computed using the cardinality conditions

$$
l_{\mu}\left(x_{j}\right)=\delta_{\mu j}, j=1,2, \ldots, m ; \mu=1,2, \ldots, m .
$$


As it is shown in Wu Zong-Min and Schaback [18], the values of the cardinal functions $l_{\mu}(x)$ at a fixed point $x$, can be also obtained from the solution of a conditional minimization problem. For details on multiquadric interpolation, we refer for example to Bardy [8], Powell [15], Buhmann and Dyn [6], Kansa and Carlson [11] and the references therein.

Descritizing equation (1.1) at points $x_{n j}$ we obtain the equations

$$
\begin{gathered}
y_{n j}=f\left(x_{n j}\right)+\sum_{i=0}^{n-1} h_{i} \int_{0}^{1} \frac{H\left(x_{n j}, x_{i}+h_{i} s, y\left(x_{i}+h_{i} s\right)\right)}{\left(x_{n j}-x_{i}-h_{i} s\right)^{\alpha}} d s \\
+h_{n} c_{j} \int_{0}^{1} \frac{H\left(x_{n j}, x_{n}+h_{n} c_{j} s, y\left(x_{n}+h_{n} c_{j} s\right)\right)}{\left(x_{n j}-x_{n}-h_{n} c_{j} s\right)^{\alpha}} d s
\end{gathered}
$$

$j=1,2, \ldots, m ; n=0,1, \ldots, N-1$. Approximating the $y$ values by $(2.6)-(2.8)$ with $x_{j}=c_{j}$ we obtain

$$
\begin{gathered}
y_{n j}=f\left(x_{n j}\right)+\sum_{i=0}^{n-1} h_{i}^{1-\alpha} \int_{0}^{1} \frac{H\left(x_{n j}, x_{i}+h_{i} s, \sum_{k=1}^{m} l_{k}(s) y_{i k}\right)}{\left(A_{n j i}-s\right)^{\alpha}} d s \\
\vdots \quad\left(h_{n} c_{j}\right)^{1-\alpha} \int_{0}^{1} \frac{H\left(x_{n j}, x_{n}+h_{n} c_{j} s, \sum_{k=1}^{m} l_{k}(s) \sum_{\lambda=1}^{m} l_{\lambda}\left(c_{j} c_{k}\right) y_{n \lambda}\right)}{(1-s)^{\alpha}} d s \\
j=1,2, \ldots, m_{i} i=0,1, \ldots, n-1 ; n=0,1, \ldots, N-1,
\end{gathered}
$$

where

$$
A_{n j i}=\left(x_{n}+h_{n} c_{j}-x_{i}\right) / h_{i} .
$$

Equations (2.10) are the exact multiquadric collocation methods. The discrete ones are obtained by replacing the integrals by Gauss quadrature rules. One and two point Gauss rules have been derived in Branca [2] for the numerical solution of weakly-singular Volterra integrai equations of the first kind. The abscissae and weights for any point Gauss rule with a number of different weight functions can be found in Gautschi [7]. Replacing the first and second sum of equations (2.10) with a p-point Gauss rule with weights and abscissae respectively,

$$
\left(w_{\mu}^{(n, i, j)}, s_{\mu}^{(n, i, j)}\right),\left(\tilde{w}_{\mu}, \tilde{s}_{\mu}\right), \mu=1,2, \ldots, p
$$

we obtain the discrete multiquadric equations

$$
\begin{aligned}
& y_{n j}=f\left(x_{n j}\right)+\sum_{i=0}^{n-1} h_{i}^{1-\alpha} \sum_{\mu=1}^{p} w_{\mu}^{(n, i, j)} H\left(x_{n j}, x_{i}+h_{i} s_{\mu}^{(n, i, j)}, \sum_{k=1}^{m} l_{k}\left(s_{\mu}^{(n, i, j)}\right) y_{i k}\right) \\
& +\left(h_{n} c_{j}\right)^{1-\alpha} \sum_{\mu=1}^{p} \tilde{w}_{\mu} H\left(x_{n j}, x_{n}+h_{n} c_{j} \tilde{s}_{\mu}, \sum_{k=1}^{m} l_{k}\left(\tilde{s}_{\mu}\right) \sum_{\lambda=1}^{m} l_{\lambda}\left(c_{j} c_{k}\right) y_{n \lambda}\right)
\end{aligned}
$$




$$
j=1,2, \ldots, m ; n=0,1, \ldots, N-1 .
$$

Another possibility which was tried is to start from equation (2.9) and approximate the $H$ function by a multiquadric appraximation of the form (2.6)-(2.8) and then use Gauss rules for the weight integrals which now are of the form

$$
\int_{0}^{1} \frac{\operatorname{lo}(s)}{\left(A_{n j i}-s\right)^{\alpha}}, \quad \int_{0}^{1} \frac{\operatorname{lr}(s)}{(1-s)^{\alpha}} d s
$$

and $A_{n j i}, l_{r}(s), r=1,2, \ldots, m$ are given by $(2.11),(2.7)$ respectively.

\section{NUmerical RESULtS}

Numerical results are presented for one example:

1) $y(x)=\ln (1+x)-2 x^{0.5}-\frac{4}{3} x^{1.5}+\int_{0}^{x} \frac{e^{y(s)}}{\sqrt{(x-s)}} d s$, with true solution $y(x)=$ $\ln (1+x)$ (constructed).

The numerical results are obtained with the Radau II points $\left(c_{1}=1 / 3, c_{2}=1\right)$. The value of $R$ was chosen after extensive simulations with a number of different $R$ values.

The resulting nonlinear equations were solved using routine SNSQE of Kahaner, Moler and Nash [10]. A tolerance equal to 1.E-4 was used. The results with heading "MQ" were obtained using equations (2.13).

Table 1. Example 1, $m=2,2$-point Gauss rule $(p=2)$

\begin{tabular}{|c|c|c|c|c|}
\hline & Polynomial & Spline & Augmented & multiquadric \\
\hline$x$ & $h=0.05$ & $h=0.025$ & $h=0.05 . R=24$ & $h=0.025, R=48$ \\
\hline 0.1 & $0.41 \mathrm{E}-5$ & $0.33 \mathrm{E}-6$ & $0.62 \mathrm{E}-5$ & $0.29 \mathrm{E}-5$ \\
0.2 & $0.27 \mathrm{E}-4$ & $0.39 \mathrm{E}-5$ & $0.32 \mathrm{E}-4$ & $0.31 \mathrm{E}-5$ \\
0.3 & $0.70 \mathrm{E}-4$ & $0.11 \mathrm{E}-4$ & $0.79 \mathrm{E}-4$ & $0.26 \mathrm{E}-5$ \\
0.4 & $0.15 \mathrm{E}-3$ & $0.24 \mathrm{E}-4$ & $0.17 \mathrm{E}-3$ & $0.34 \mathrm{E}-5$ \\
0.5 & $0.34 \mathrm{E}-3$ & $0.54 \mathrm{E}-4$ & $0.38 \mathrm{E}-3$ & $0.27 \mathrm{E}-5$ \\
0.6 & $0.78 \mathrm{E}-3$ & $0.12 \mathrm{E}-3$ & $0.87 \mathrm{E}-3$ & $0.24 \mathrm{E}-5$ \\
0.7 & $0.19 \mathrm{E}-2$ & $0.31 \mathrm{E}-3$ & $0.21 \mathrm{E}-2$ & $0.74 \mathrm{E}-5$ \\
0.8 & $0.52 \mathrm{E}-2$ & $0.84 \mathrm{E}-3$ & $0.58 \mathrm{E}-2$ & $0.13 \mathrm{E}-4$ \\
0.9 & $0.16 \mathrm{E}-1$ & $0.28 \mathrm{E}-2$ & $0.18 \mathrm{E}-1$ & $0.35 \mathrm{E}-4$ \\
1.0 & $0.56 \mathrm{E}-1$ & $0.86 \mathrm{E}-2$ & $0.62 \mathrm{E}-1$ & $0.12 \mathrm{E}-3$ \\
\hline
\end{tabular}

\section{Concluding Remarks}

In this paper the application of collocation methods based on approximations with multiquadrics to Volterra integral with weakly-singular kernel was considered. The above results show that multiquadric collocation methods can be more accurate than the polynomial spline collocation methods with the same collocation parameters. Results obtained with two more examples though, were almost identical for the two classes of methods. 
More tests are needed with more examples and theoretical analysis so that to identify classes of functions where the multiquadrics approximations give considerably more accurate results in the weakly-singular case. Also tests with multiquadric augmented by a polynomial of higher degree than that considered here. Orders of convergence at least $O\left(h^{2}\right)$ were observed with $m=2$ for the Radau II points. The accuracy of the results depends on the successful choice of the multiquadric parameter $R$. We are continuing research on the derivation of a method for choosing $R$, on an error analysis for obtaining the order of convergence. It will be also interesting to see how the methods perform in solving integro-differential equations with weakly singular kernels.

\section{REFERENCES}

1. Abelman, S., A retional besie for second-kind Abel integral equetions, J. Comput. Applied Math. 34 (1991), 281-290.

2. Brance, H.W., The nonlinear Volterre equation of Abel's kind and its numerical treatment, Computing 20 (1987), 307-324.

3. Brunner, H., The numerical solution of weakly-singular Volterra integral equetions by collocation on graded meahes, Math. Comp. 45 (1985), 417-437.

4. Brunner, H. and Van der Houwen, P.J., The nwmerical solution of Volterre equations, CWI Monographa 3 (1986), North Holland, Amaterdam.

5. Brunner, H., Riele, H. J. J., te, Volterra-type integral equations of the second kind with nonumooth solutiona:high order methods based on collocation techniques, J. Integral Equations 6 (1984), 187-203.

6. Buhmann, M.D. and Dyn, N., Error estimates for multiquadric interpolation, pp. 51-58 in Curoes and Surfaces, Laurent, P.J., LeMéhauté, A., Schumaker, L.L. (eds.), Academic Press, 1991.

7. Gautachi, W., Algorithm 9s1, Gasssian quadroture formulas, Collected Algorithms from ACM, 1968, pp. 331-P1-331-P5.

8. Handy, R.L., Multiquadric equetions of topogrephy and other irregular swrfaces, J.Geophys. Res. 76 (1971), 1905-1915.

9. Hoog, F. R., de and Weise, R., High order methods for a class of Volterre integral equations urith weakly singuler kernels, SLAM J. Numer. Anal. 11 (1974), 1166-1180.

10. Kahaner, D., Moler, C. and Naeh, S., Numerical methoda and softwere, Prentice Hall, 1989.

11. Kanes. E.J. , Carlaon, R.E., Improved accuracy of multiquadric interpolation using variable shape paremeters, Comput. Math. Appl. 24 (1992), 99-120.

12. Linz, P., Numerieal methods for Volterre integral equations with singular kernels, SIAM J. Numer. Anal. 6 (1969), 365-374.

13. Lubich. Ch., Fractional linear multistep methods for Abel-Volterrs integral equations of the seeond kind, Math. Comp. 45 (1985), 463-469.

14. Makroglou, A., Multiquadric collocetion methods in the numerical solution of Volterra integral and integro-differential equations, to appear in AMS Proceedings of Symposia of Applied Mathematica.

15. Powell, M.J.D., Univariate multiquadrie interpolation : some recent results, DAMTP 1990/NA9, Dept. of Applied Mathematica and Theoretical Physica, Unir. of Cambridge, England, 1990.

16. Rieie, H. J. J., te, Collocation methods for weakly singular second-kind Volterta integral equations with non-smooth solutiens, IMA J. Numer. Anal. 2 (1982), 437-449.

17. Riley, B.V., The numerical solvtion of Volterre integral equations with nonsmooth solutions based on sine approximations. Applied Num. Math. 9 (1992), 249-257.

18. Wu, Zong-Min and Schaback, R., Local error estimates for radial basis function interpolation of scattered data, IMA J. Numer. Anal. 13 (1993), 13-27. 

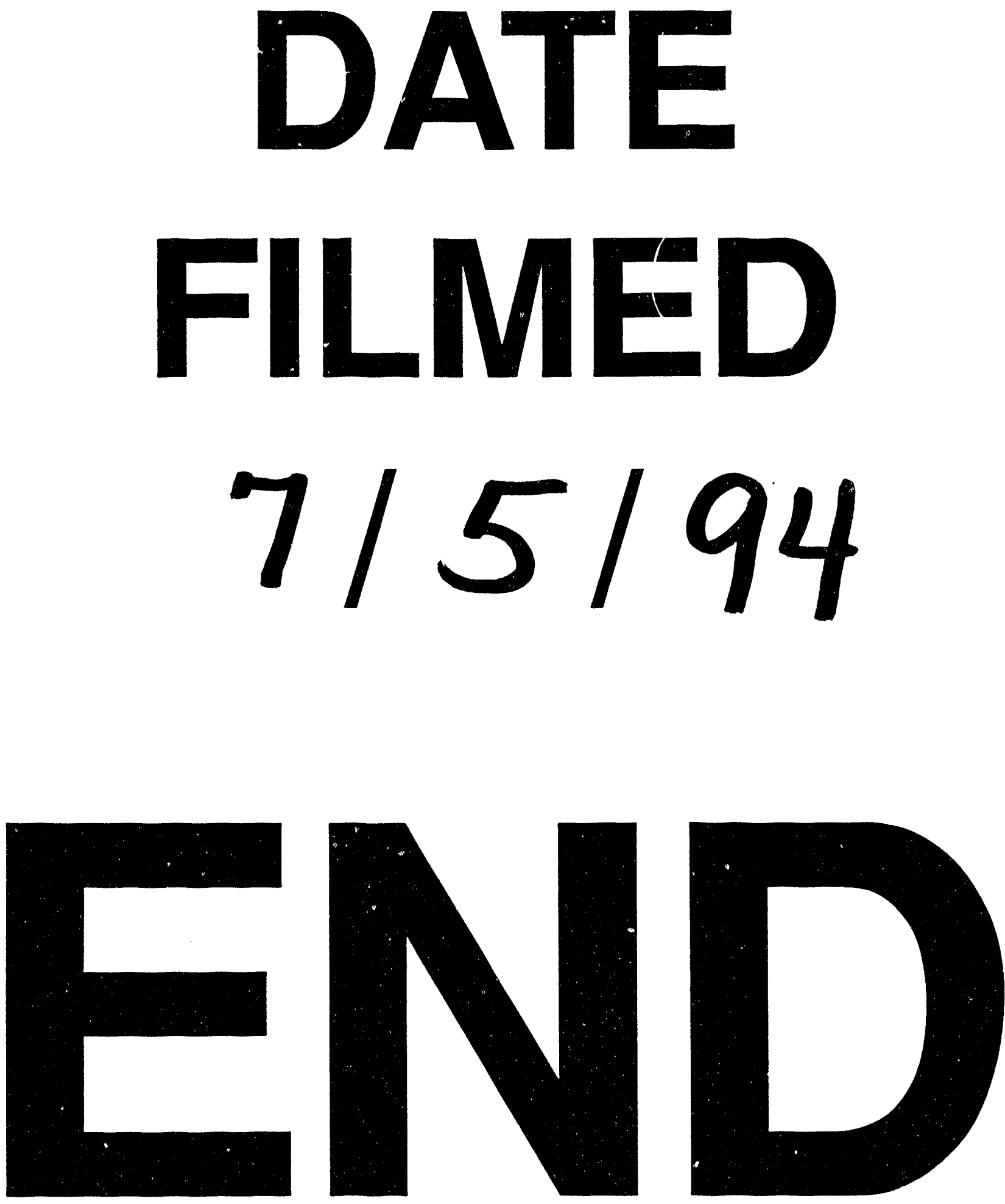
